\title{
Diffusion Anisotropy
}

National Cancer Institute

\section{Source}

National Cancer Institute. Diffusion Anisotropy. NCI Thesaurus. Code C69227.

A property of tissues such that a substance shows variable rates of diffusion in different spatial dimensions. 